\title{
Hábitos midiáticos e ressignificações de estudantes da rede pública ${ }^{1}$
}

Maria Aparecida Baccega

Livre-docente em comunicação pela Escola de Comunicações e Artes da Universidade de São Paulo (ECA/USP). Atualmente é docente, pesquisadora e orientadora do Programa de Pós-graduação em Comunicação e Práticas de Consumo (PPGCOM) da Escola Superior de Propaganda e Marketing de São Paulo (ESPM-SP). Coordena a rede nacional OBITEL Brasil pela ESPM-SP.

E-mail: mabga@usp.br

Camilla Rodrigues Netto da Costa Rocha

Doutoranda no Programa de Pós-graduação em Comunicação e Práticas de Consumo (PPGCOM) da Escola Superior de Propaganda e Marketing de São Paulo (ESPM-SP), na qualidade de bolsista da Coordenação de Aperfeiçoamento de Pessoal de Nível Superior (Capes), modalidade Programa de Suporte à Pós-graduação de Instituições de Ensino Particulares (Prosup) integral. E-mail: camilla@costarocha.com.br

Resumo: Neste artigo temos por objetivo investigar o lugar do campo da comunicação/educação na conformação da realidade social buscando compreender, por um lado, o espaço ocupado pelos meios de comunicação no cotidiano dos estudantes e, por outro, as ressignificações desses estudantes frente à temática da família homoafetiva, pautada pela telenovela. Para tanto, adotamos como itinerário metodológico a abordagem quantitativa para investigar os hábitos midiáticos dos estudantes de duas escolas públicas do Ensino Médio e, posteriormente, a abordagem qualitativa, buscando entender, por meio da análise de discurso de linha francesa (ADF), seus usos e apropriações quanto à telenovela.

Palavras-chave: comunicação; comunicação/educação; telenovela; análise de discurso; família homoafetiva.
Abstract: This article aims to investigate the role of the communication/education field in shaping the social reality, aiming to understand, on the one hand, the role played by the media in the student's daily lives and, on the other, what are the resignifications done by these students in relation the theme of gay families, which was approached by the telenovela. For that end, we have adopted as a methodological itinerary the quantitative approach to investigate the media habits of students in two public high schools and, later on, the qualitative approach, aiming to understand, through the French Discourse Analysis (FDA), its use and appropriation in regard to the telenovelas.

Keywords: communication; communication/ education; telenovelas; discourse analysis; gay family. 
comunicação \& educação • Ano XXIII • número 1 • jan/jun 2018

2. BACCEGA Maria Aparecida. Comunicação/ educação e a construção de uma nova variável histórica. Comunicação \& Educação, São Paulo, v. 14 , n. 3 , p. $19-28$, set./ dez. 2009.

3. Ibidem, p. 20

4. Consideramos jovens todos aqueles com idade entre 15 e 24 anos (conforme o Instituto Brasileiro de Geografia e Estatística - IBGE) e, neste artigo, limitamo-nos aos estudantes do Ensino Médio $\left(1^{\circ}\right.$ e $3^{\circ}$ ano). INS TITUTO BRASILEIRO DE GEOGRAFIA E ESTATÍSTICA. População jovem no Brasil. Rio de Janeiro: IBGE, 2004. Disponível em: <https://ww2.ibge. gov.br/home/estatistica/ populacao/populacao_jovem_brasil/default.shtm>. Acesso em: 2 jan. 2018.

5. MEMÓRIA GLOBO. Amor à vida. Rio de Janeiro: Globo, 2014a. Disponível em: <http:// memoriaglobo.globo. com/programas/entretenimento/novelas/amor-a-vida/amor-a-vida-trama-principal.htm>. Acesso em: 2 jan. 2018

6. MEMÓRIA GLOBO. Em família. Rio de Janeiro: Globo, 2014b. Disponível em: <http://memoriaglobo.globo.com/programas/ entretenimento/novelas/ em-familia/em-familia-trama-principal.htm>. Acesso em: 2 jan. 2018.

7. TOALDO, Mariângela; JACKS, Nilda. Consumo midiático: uma especificidade do consumo cultural, uma antessala para os estudos de recepção. In: ENCONTRO ANUAL DA COMPÓS, 22., 2013, Salvador. Anais... Salvador: UFBA, 2013.

8. CANCLINI, Néstor García. El consumo cultural en México. México: Grijalbo, 1993.

\section{INTRODUÇÃO}

Calcamos este artigo em uma das chaves de leitura que propiciam a compreensão do que é a essência do campo da comunicação/educação: a perspectiva de que os meios de comunicação passem a ocupar um espaço na realidade social de forma a disputar, em equidade de condições, a hegemonia da formação dos sentidos sociais com duas outras agências socializadoras, outrora predominantes: a família e a escola. Qual o diálogo possível entre essas agências? Essa é uma das perguntas que impulsionam as reflexões do campo da comunicação/educação².

Em retomada acerca do dialogismo e da dialética que compõem os embates travados via linguagem, no seio social, Baccega ${ }^{3}$ aponta o campo da comunicação/educação como lugar privilegiado para desvelar a práxis, que "desenha e redesenha os sentidos, no caminho da tradição ou da ruptura, do tradicional ou do novo, da permanência ou da mudança".

Neste artigo, temos por objetivo investigar esse lugar privilegiado do campo da comunicação/educação na realidade social, buscando entender o espaço ocupado pelos meios de comunicação no cotidiano do público jovem ${ }^{4}$. Interessa perceber, em um primeiro momento, os hábitos midiáticos dos estudantes de escolas públicas do Ensino Médio e, posteriormente, seus usos e as apropriações quanto ao produto cultural telenovela.

Elegemos como objeto empírico para nossa análise duas telenovelas da Rede Globo: Amor à vida, exibida entre 20 de maio de 2013 e 31 de janeiro de $2014^{5}$, e Em família, exibida entre 03 de fevereiro de 2014 e 18 de julho $2014^{6}$. Interessa-nos, em relação à primeira, a trama paralela do personagem Félix e, na segunda, a trama paralela da personagem Clara. Isso porque voltamos nosso olhar para as construções e ressignificações de sentidos em torno da família homoafetiva, presentes nessas narrativas a partir dos personagens eleitos. Acreditamos, com isso, responder à seguinte problemática: de que modo tanto os hábitos midiáticos quanto a recepção dos jovens podem nos indicar que os meios de comunicação disputam um espaço pela hegemonia na construção dos sentidos sociais?

Posto isso, cabe diferenciar o que, neste artigo, entendemos por consumo midiático e o que entendemos por recepção. Assim o fazemos a partir de Toaldo e Jacks ${ }^{7}$, cujo título do artigo datado de 2013 já deixa antever a posição das autoras nessa questão: "Consumo midiático: uma especificidade do consumo cultural, uma antessala para os estudos de recepção”. É a partir dos modelos de Canclini ${ }^{8}$ que as autoras propõem o consumo cultural enquanto aquele que resulta das apropriações dos sujeitos em que prevalece a dimensão simbólica frente à econômica. Com isso, distinguem consumo de consumo cultural.

Feita essa distinção, as autoras apresentam uma vertente do consumo cultural, introduzindo o consumo midiático em duas vertentes: uma que foca no papel da mídia sobre o consumo, funcionando então o aparato midiático como 
mediador de um consumo material, e uma segunda, que congrega o consumo ofertado pela própria mídia a partir de seus produtos midiáticos. Esclarecem que, no contexto do consumo midiático, "interessa saber o que os indivíduos consomem da mídia (meios e produtos/conteúdos), a maneira com que se apropriam dela (do que consomem - como a utilizam) e o contexto em que se envolvem com ela (lugares, maneiras, rotinas...)" ${ }^{9}$.

Vemos com isso que, neste artigo, tratamos do consumo midiático enquanto diagnóstico dos hábitos midiáticos dos sujeitos, e não de acordo com a primeira concepção, que lhe confere o caráter de mediação para um consumo material. Isso porque - como será detalhado na metodologia -, na etapa quantitativa da pesquisa de campo, contemplamos os conteúdos midiáticos consumidos pelos estudantes, os modos de consumo desses conteúdos e os contextos em que tal consumo se efetua (por meio do mapa de consumo cultural).

Todavia, na etapa qualitativa o que averiguamos não foi, majoritariamente, o consumo midiático dos jovens, mas o envolvimento deles com as telenovelas. A dimensão do consumo midiático não envolve:

A análise de respostas dos receptores aos conteúdos de um programa específico, nem as consequências desse envolvimento com tal programa ou gênero (as influências dos conteúdos midiáticos na vida dos indivíduos), o que era realizado pelos estudos dos efeitos e, atualmente, em alguma medida, pelos estudos de recepção ${ }^{10}$.

Interessaram-nos perceber, nesse momento, as relações estabelecidas pelos estudantes com as duas telenovelas e, a partir disso, suas interpretações e processos de construção de sentido de modo mais amplo do que aquele circunscrito apenas na experiência midiática em si. Enfrentamos, portanto, em um primeiro momento, o consumo midiático e, posteriormente, a recepção, pois "no caso dos estudos de recepção, trata-se de detalhar aspectos do fenômeno midiático na dimensão de seus conteúdos, fechando o foco de observação, o que não significa dispensar uma análise do consumo midiático"11.

Além disso, cabe justificar que optamos por trabalhar com jovens do Ensino Médio por encontrarmos aí uma possibilidade de investigação acerca da leitura crítica dos meios de comunicação. Já a escolha das escolas públicas justifica-se pela nossa impossibilidade de ingresso em escolas particulares. A intenção inicial da pesquisa era a de comparar duas escolas, uma pública e outra particular, e compreender o cenário socioeconômico de cada uma delas, bem como as percepções dos alunos em cada situação. Todavia, as aproximações com as escolas particulares se mostraram de todo frustradas ${ }^{12}$. Desse modo, fomos a duas escolas públicas: JSA, que fica localizada na Estrada Velha de Sorocaba, no bairro Granja Viana, em Cotia; e PRP, situada no bairro Chora Menino, zona norte da capital paulista, ambas no estado de São Paulo. Na primeira, ficamos com duas turmas, $1^{\circ}$ ano B e $3^{\circ}$ ano A, enquanto na segunda conversamos com o $3^{\circ}$ ano A, todas do Ensino Médio.
9. TOALDO, Mariângela; JACKS, Nilda, op. cit., p. 7.

10. Ibidem, p. 9.

11. Ibidem, p. 8.

12. Ao longo da pesquisa, tentamos quatro escolas e em todas recebemos semelhante justificativa para a recusa: a de que nossa ida interromperia o calendário de final de ano (dezembro de 2016), que possui prazos apertados em virtude do Exame Nacional do Ensino Médio (Enem) e das provas finais. Diante de tais negativas, buscamos outras opções de escolas e conseguimos acessar duas estaduais. 


\section{PERCURSO METODOLÓGICO}

Uma vez em campo, adotamos como procedimentos metodológicos norteadores tanto aqueles que provêm da pesquisa quantitativa - e que possibilitaram nossa aproximação e o conhecimento do perfil socioeconômico e dos hábitos de consumo midiático dos estudantes - quanto os da pesquisa qualitativa.

Imperam, para fins de exame desse artigo, as conclusões a que chegamos no momento do emprego do mapa de consumo cultural (abordagem quantitativa), bem como pelo grupo de discussão, que prima por uma abordagem qualitativa de pesquisa. O mapa foi respondido pelos estudantes do terceiro ano. Já o grupo de discussão foi realizado com todas as turmas (duas do terceiro ano e uma do primeiro), após instar-lhes o contato com alguns trechos das telenovelas selecionadas.

Nossas análises qualitativas calcam-se na perspectiva teórico-metodológica da análise de discurso de linha francesa (ADF). Quando Bakhtin ${ }^{13}$ problematiza a filosofia da linguagem, torna manifesta a imbricação entre linguagem e social. Trazendo a marca do signo linguístico e ideológico pelo "horizonte social de uma época e de um grupo social determinados"14, o autor deixa antever como corolário a primazia do social nos processos decorrentes da linguagem. Também para Baccega ${ }^{15}$ o sujeito se constitui na interação social por meio da linguagem, na medida em que "cada palavra materializa a prática social do grupo ou classe social que a utiliza e que a modifica permanentemente no seu cotidiano, a partir de suas vivências".

Assim, vislumbramos que não é possível a existência social humana sem a

13. BAKTHIN, Mikhail. Marxismo e filosofia da linguagem: problemas fundamentais do método sociológico da linguagem. São Paulo: Hucitec, 2014.

14. Ibidem, p. 45

15. BACCEGA, Maria Aparecida. Comunicação \& Educação: do mundo editado à construção do mundo. Comunicação e Informação, Goiânia, v. 2, n. 2, p. 176-187, jul./dez. 1999 , p. 8.

16. ORLANDI, Eni. Análise de discurso: princípios e procedimentos. Campinas: Pontes, 2013, p. 21.

17. Ibidem, p. 15.

18. BACCEGA, Maria Aparecida. Palavra e discurso: história e literatura. São Paulo: Ática, 1995, p. 48.

19. BAKHTIN, Mikhail, op. cit., p. 47.

20. ORLANDI, Eni, op. cit. linguagem e, consequentemente, sem o discurso. Isso porque "as relações de linguagem são relações de sujeitos e de sentidos e seus efeitos são múltiplos e variados. Daí a definição de discurso: o discurso é efeito de sentidos entre locutore"” ${ }^{\text {. }}$ Para Orlandi, percussora dos estudos da ADF no Brasil, a "análise de discurso concebe a linguagem como mediação necessária entre o homem e a realidade natural e social"17.

Em Baccega, temos que "a língua não é apenas um instrumento com a finalidade de transmitir informações. É um todo dinâmico que abarca o movimento da sociedade: por isso, é lugar de conflitos. Esses conflitos se 'concretizam' nos discursos"18. Para Bakhtin, "o signo se torna a arena onde se desenvolve a luta de classes"19, o que traz a ambivalência do signo como norte para pensarmos o fato de que os sentidos sociais estão sempre em formação, ou seja, nunca completamente formados.

Daí que consideramos imperioso, se quisermos pensar a realidade, fazê-lo a partir da compreensão do que são os discursos. Para Orlandi ${ }^{20}$, essa é a contribuição da análise de discurso: colocar todos nós, enquanto sujeitos e pesquisadores, em estado de reflexão. Assim, neste artigo, por caminharmos rumo à compreensão do que mora na polifonia dos discursos que provêm dos alunos de JSA e PRP frente às produções midiáticas de Em família e Amor à vida, empregamos a perspectiva teórico-metodológica da ADF. 


\section{FILIAÇÕES TEÓRICAS: TELENOVELA E CAMPO DA COMUNICAÇÃO/EDUCAÇÃO}

Escolhemos a telenovela em virtude de sua importância advinda do fato de que sua narrativa coloca em voga um novo espaço público:

Alçada à posição de principal produto de uma indústria televisiva de grandes proporções, a novela passou a ser um dos mais importantes e amplos espaços de problematização do Brasil, indo da intimidade privada aos problemas sociais. Essa capacidade sui generis de sintetizar o público e o privado, o político e o doméstico, a notícia e a ficção, o masculino e o feminino, está inscrita na narrativa das novelas que combina convenções formais do documentário e do melodrama televisivo ${ }^{21}$.

Considerada transclassista por Baccega ${ }^{22}$, com uma "penetração intensa na sociedade brasileira devido à sua peculiar capacidade de criar e de alimentar um 'repertório comum"”, a telenovela está ao alcance de diversas pessoas e sua narrativa chega a muitos, sem distinção de raça, sexo ou classe social. É nessa circulação ampla que a telenovela, ao pautar importantes temáticas sociais, coloca, ao alcance da maioria, a possibilidade do diálogo sobre os fatos ali narrados.

Então, nesse sentido, passa a nos interessar o potencial educativo da telenovela. Ao mesclar público e privado, ou seja, ao lançar para a esfera pública dramas que antes pareciam ser tão íntimos e únicos, de modo a construir um espaço comum de identificação e projeção, a telenovela vai "sintetizar problemáticas amplas em figuras e tramas pontuais e, ao mesmo tempo, sugerir que dramas pessoais e pontuais podem vir a ter significado amplo" ${ }^{44}$. Tal identificação ressoa com o que Baccega ${ }^{25}$ lembra como "persuasão", resultante da facilidade que a telenovela tem em expor conceitos e dialogar com a sociedade, constituindo-se em espaço potente para a educação.

A pesquisa que sustenta essas reflexões é proveniente de uma dissertação de mestrado (cf. Rocha ${ }^{26}$ ) e compreendeu nossa ida a duas escolas públicas estaduais, JSA e PRP. Recortamos algumas ponderações oriundas dessa investigação para reflexionar neste artigo, de que maneira, a partir de análise do consumo midiático e do discurso dos alunos, podemos ter indicativos de que os meios de comunicação disputam um espaço pela hegemonia na construção dos sentidos sociais. O foco recai, portanto, no espaço que as plataformas midiáticas ocupam na vida desses sujeitos; qual o papel que desempenham na construção de sentidos - o que intentamos perceber a partir do debate em torno da família homoafetiva.

Tecendo algumas considerações acerca da existência do campo da comunicação/educação, sobreleva como relevante perceber que, para esse campo de estudo, é fundamental ultrapassar a noção de que estudar comunicação é recair no estudo das tecnologias. Esse campo propugna com constância pelo cuidado de não reduzir, jamais, a comunicação ao aparato midiático e nem ao tecnológico.

Além disso, "este processo comunicação/educação merece o lugar de segmento prioritário das teorizações e das pesquisas no campo da comunicação,
21. LOPES, Maria Immacolata Vassalo de. Telenovela como recurso comunicativo. Matrizes, São Paulo, ano 3, n. 1, p. 21-47, ago./dez. 2009, p. 26.

22. BACCEGA, Maria Aparecida. Narrativa ficcional de televisão: encontro com os temas sociais. Comunicação \& Educação, São Paulo, n. 26, p. 7-16, jan./abr. 2003.

23. LOPES, Maria Immacolata Vassalo de, op. cit., p. 22.

24 Ibidem, p. 27.

25. BACCEGA, Maria Aparecida, op. cit., 2003.

26. ROCHA, Camilla Rodrigues Netto da Costa. O conceito de família na telenovela: um estudo sobre sua recepção. 2017. 170 f. Dissertação (Mestrado em Comunicação e Práticas de Consumo) Escola Superior de Propaganda e Marketing, São Paulo, 2017. 
pois permite que se leve em conta, sobretudo, o papel da mídia na configuração da cultura” ${ }^{27}$. É tarefa do campo da comunicação/educação pensar a consolidada imbricação entre mídia e cultura, de modo que passam a ser contribuições relevantes para os teóricos desse campo quaisquer reflexões que se proponham a compreender o cenário contemporâneo atinente à mídia, em confluência com a cultura (e não no dispositivo midiático, tão e somente).

Porém, o que nos interessa nesta reflexão é ainda outro viés, qual seja, aquele debate que advém de um dos escopos do campo da comunicação/educação, o de propor diálogo entre as várias agências de socialização - família, igreja, escola e meios de comunicação. O viés a que nos referimos é justamente a disputa pela hegemonia, por parte dessas agências socializadoras, para a formação dos sentidos sociais que atravessam e compõem os sujeitos. Isso porque é intrínseco ao debate do campo da comunicação/educação pensar sobre os meios de comunicação e suas realidades enquanto agência socializadora que atua na disputa pela hegemonia na formação dos sentidos sociais por meio de suas proposições discursivas, sejam verbais, imagéticas, sonoras ou estéticas, e é nisso que centramos nossa atenção.

\section{EM CAMPO: INVESTIGAÇÕES COM OS ESTUDANTES}

Na primeira escola, JSA, ficamos com duas turmas, ambas do Ensino Médio: $1^{\circ}$ ano B (pelo período de uma aula) e $3^{\circ}$ ano A (pelo período de duas aulas). Na segunda, PRP, conversamos com o $3^{\circ}$ ano A, também do Ensino Médio e também ao longo de duas aulas. De nossa observação, quando da ida às duas escolas, sobreleva a diferença em relação ao contexto socioeconômico. A começar pela localização, pois a PRP está inserida perto de residências que podemos afirmar se tratarem de classe média-alta, enquanto JSA fica em uma região bem mais isolada do grande centro urbano e ao lado de uma comunidade. A maior parte de seus estudantes, inclusive, mora nesse local.

Na etapa quantitativa da pesquisa, buscamos nos aproximar dos estudantes dos terceiros anos das duas escolas, a fim de conhecer um pouco mais sobre o perfil desses jovens, bem como seus hábitos de consumo midiático. Para tanto, valemo-nos do mapa de consumo cultural que foi aplicado para 22 alunos da escola estadual PRP e para 19 alunos da escola estadual JSA.

Adentrando na esfera dos hábitos culturais desses jovens, a fim de investigar o que consideramos como consumo midiático, o perfil é bastante semelhante quanto à questão de assistir à televisão: a esmagadora maioria assiste, nas duas escolas, sendo que apenas quatro alunos em cada escola informaram não fazê-lo. $\mathrm{O}$ que chamou atenção foi a frequência, uma vez que apenas metade dos alunos assiste à televisão diariamente na PRP e na JSA, apenas 36,84\% a assistem todos os dias. O perfil socioeconômico evidencia-se em parte na questão da TV por assinatura, pois enquanto 72,73\% dos alunos de PRP têm o serviço, $57,89 \%$ dos alunos de JSA não têm. 
Dentre os canais favoritos, o cenário se mostra bastante pulverizado, mas, ainda assim, a maior parte dos alunos assinalou a Rede Globo como canal mais assistido. Quanto à natureza do programa que mais assiste, a maior parte dos alunos da JSA assinalou novela e entretenimento/humor. Já na PRP, o mais assistido é esporte, seguido de novela e entretenimento/humor. A esmagadora maioria dos jovens conversa com alguém enquanto assiste à televisão (68,18\% dos alunos da PRP e 64,71\% dos alunos da JSA). Dos assuntos e com quem são comentados, destacamos:

\section{PRP}

Com meus pais; sobre o que estamos assistindo.

Minha mãe; sobre situações semelhantes às que vemos na TV.

Irmã; normalmente sobre o programa.

Vó e mãe; sobre o que se passa.

\section{JSA}

Com a minha mãe e meu irmão, sobre novelas e filmes.

Sobre o que estamos assistindo; minha mãe.

Novela e com minha amiga.

Observamos uma indicação consiste da presença da família nas conversas, o que se confirma quando perguntados sobre com quem assistem à televisão: $84,21 \%$ na PRP e 52,94\% na JSA responderam ser com a família. Além disso, a maior parte deles, nas duas escolas, fazem outras coisas quando estão diante da telinha, sendo o mais apontado a utilização do celular na PRP, bem como refeições, nas duas escolas. Sobre a finalidade com que assistem à TV, os jovens informaram, em sua maioria, ser para diversão e para obter informação, igualmente nas duas escolas.

Quanto a estar assistindo atualmente a alguma telenovela, a maioria dos alunos da PRP está assistindo (59,09\%), enquanto que na JSA a maior parte dos alunos não está $(66,67 \%)$. Isso se justifica, provavelmente, pelo fato de os alunos da JSA frequentarem a escola no período da noite. Dentre as novelas que receberam destaque, na PRP foi Haja coração, enquanto na JSA foi Malhação.

Ainda no que se refere às telenovelas, os jovens entrevistados acreditam que elas influenciam no comportamento das pessoas - apenas quatro alunos em cada escola disseram que não -, e quanto a ser positiva ou negativa, chamamos atenção para o fato de que nas duas escolas prevalece a percepção de que influência é mutuamente positiva e negativa, e não uma forma ou outra.

Os alunos relataram, quando das respostas ao questionário, algumas situações que presenciaram ou viveram que os levou a acreditar na influência da telenovela, tais como:

\section{PRP}

Já vi diversas discriminações com a sociedade LGBT. Sou totalmente a favor e luto pelo respeito igual de todos.

Bom, comigo aconteceu de ver fatos reais e mudei minhas atitudes e forma de pensar. 
Amigos meus já foram preconceituosos por se inspirarem em um personagem de novela.

Uma novela já influenciou um amigo a "mudar" de "opção" sexual

\section{JSA}

Para comprar coisas, influenciar as pessoas a serem consumistas, a quantidade de filhos, a forma de falar ou se expressar, por exemplo a novela Rebeldes tinha muitas meninas que imitavam a Alice, andam e falam, até os lacinhos que ela usava, ou a Roberta, pelas mechas coloridas.

É notável ver a influência que a mídia traz, um exemplo são milhares de mulheres que não se aceitam por não ter um pouco das suas características presentes em uma novela.

Bordões, se assisto muito começo agir, falar, igual o meu personagem favorito. Modo de falar dos atores que pega no dia a dia.

No modo de se vestir, falar etc.

Sobre as telenovelas que foram objetos de nossa pesquisa, metade dos alunos assistiram a Amor à vida na JSA, e apenas 31,282\% dos alunos da PRP afirmaram tê-la assistido. Já à telenovela Em família, de acordo com o assinalado no mapa de consumo cultural, a esmagadora maioria dos alunos não assistiu, em ambas as escolas $(63,64 \%$, na PRP e 88,24\% na JSA). Por algumas outras perguntas do questionário, percebemos que o engajamento dos jovens com Amor à vida e Em família foi pequeno, uma vez que não comentaram nas redes, não buscaram informações sobre as telenovelas e poucos se identificaram com personagens das tramas.

Na JSA não houve, por parte deles, nenhuma identificação com os personagens de Amor à vida, enquanto na PRP três alunos se identificaram com Félix e três com Paloma. Quanto à telenovela Em família, dois alunos da PRP se identificaram com Clara, um com Helena e outro com a família Vitti, enquanto na JSA os alunos não se identificaram com nenhum deles. Essa ausência de identificação assinalada pelos alunos da JSA não se confirmou quando responderam porque se identificaram, momento do questionário no qual os alunos que assinalaram pela não identificação trouxeram justificativas para a identificação com alguns personagens.

Por fim, sobre os personagens Félix e Clara, dois alunos da PRP marcaram Clara como poderosa e determinada. Sobre Félix, quatro alunos indicaram hot dog como uma palavra que associam com o personagem. Na JSA um aluno indicou Félix como doido e outro o designou como malvado. Ninguém da JSA opinou sobre Clara quando do preenchimento do mapa cultural.

Tendo em vista tais informações, passamos à análise do material provindo da etapa qualitativa da pesquisa empírica. Interessa-nos perceber, para fim deste artigo, os sentidos que orbitam em torno da família homoafetiva, de maneira que elegemos como categoria empírica de análise a homossexualidade. Acreditamos que, assim, podemos examinar as ressignificações dos alunos a partir das proposições discursivas de uma temática cuja pauta está no embate pela formação dos sentidos sociais a partir das telenovelas. 
No grupo de discussão realizado na escola JSA com os estudantes do primeiro ano do Ensino Médio, percebemos uma divisão entre os alunos, alguns apoiando a homossexualidade e outros a rejeitando:

A2: Gostei da do homem, do casamento, do beijo dos dois. [...] Isso daí, hoje em dia, é normal.

A3: Hoje em dia? Onde já se viu? É normal duas mulheres, agora dois homens...

A3: Onde já se viu, dois homens se beijando?

A2: É normal, igual ver mulher.

A4: É tudo pecado.

A3: Deus já fez assim: Adão e Eva, homem e mulher, os dois fica junto, não homem com homem e mulher com mulher.

Quando Baccega ${ }^{28}$ afirma que o sujeito se constitui na interação social por meio da linguagem e que "quando aprendemos uma língua, estamos apreendendo, estamos introjetando um sistema de categorias que regerão nossa percepção da realidade. E é no interior desse sistema que os objetos, os acontecimentos, os processos terão significação" ${ }^{29}$, percebemos o quanto o sistema religioso encontra-se presente na formação da visão de mundo de alguns dos estudantes, fazendo que articulem suas percepções a partir da ótica desse sistema e não de uma construção crítica, refletida e elaborada.

O debate entre os alunos da JSA ficou bastante concentrado na questão da diferença entre os gêneros quando da consideração do tema da homossexualidade. Na turma do terceiro ano, esse conflito se fez presente na fala de mais de um aluno:

A13: Não, mas é sério, tipo a minha vizinha, quando eu tava assistindo à novela, fiquei sabendo por ela, que eu até comentei. Ela não ficou surpresa quando viu duas mulheres se beijando, mas quando ela viu os dois homens se beijando, ela começou a criticar.

A8: É porque sexualizam mais as mulheres, né? Duas mulheres se beijando, colocam na nossa cabeça que é sexy, é sexy duas mulheres se beijar entre si, principalmente pra homens. Já dois homens se beijando não é uma coisa que se vê, tipo, "ai, olha que lindo, olha que sexy".

A12: Com o beijo deles mesmo, e com homem e homem e mulher com mulher, só que o homem tende a ser bem pior, como ela disse mesmo. Tem homens que gostam de ver mulheres se beijando, o que não é o meu caso, mas o homem beijar outro homem é bem mais marcante, bem mais chocante. Como tem homens que aparentam ser tudo másculo, e o homem mesmo é muito machista. E aí você vê dois homens se beijando, assim, é meio chocante.

O que desperta nossa atenção nesses discursos é a presença da questão do machismo. Se quando da análise do discurso o que "temos, como produto da análise, é a compreensão dos processos de produção de sentido e de

28. BACCEGA, Maria Aparecida, op. cit., 1999, p. 8.

29. BACCEGA, Maria Aparecida, op. cit., 1995, p. 48. 
constituição dos sujeitos em suas posições" ${ }^{30}$, vemos a constituição dos sujeitos em uma posição machista quando deparamos com uma fala como a do aluno A12. Ou seja, a própria concepção machista de ver o mundo impede que aceitem a homossexualidade como orientação sexual. Como na colocação do aluno A8, mesmo apontando que "eles" sexualizam muito as mulheres, o aluno acaba demonstrando a presença do machismo em sua própria fala, quando traz o fato de não achar sexy dois homens se beijarem.

Passando ao grupo de discussão realizado na escola PRP com os estudantes do terceiro ano do Ensino Médio, podemos observar logo de início uma diferença quanto aos alunos da JSA. Enquanto uma parte dos jovens se mostrou favorável em relação à transmissão da temática da homossexualidade na televisão, exposta nas jornadas de Félix e Clara, outros evidenciaram sua discordância e elegeram, como cena favorita, o tapa que o pai (César) desfere no filho (Félix) em razão de sua orientação sexual.

A justificativa do aluno A20 quanto ao fato de Félix ter merecido o tapa "porque ele escolheu esse caminho que eu acho que é errado" se limita ao fato de que este pensa ser errada a homossexualidade, de modo que o tapa passa a funcionar como um corretivo, uma punição merecida que o pai confere ao filho. Enquanto isso, a aluna A19 articula a necessidade de uma desconstrução acerca de temas considerados tabus na sociedade e valoriza a evidência midiática da questão da homossexualidade.

Percebemos duas instâncias discursivas, uma no aluno A20, a favor de um poder que por muito tempo coibiu a homossexualidade, colocando-a como doença por meio do discurso médico, e outro na aluna A19, que se atenta ao que Foucault ${ }^{31}$ assenta como percepção das manobras discursivas adotadas pelo poder hegemônico para manter a dominância. A aluna A19 prosseguiu no desenvolvimento de sua reflexão e colocou uma pergunta para a sala:

A19: Ninguém imagina... por exemplo, você tá assistindo à TV com o seu filho e tá passando um monte de violência e o pai aceita. Só que quando ele vê um beijo gay, eu acho que é uma desconstrução. É falar "nossa, por que ele pode assistir violência, cena de sexo e outras coisas, mas ele não pode ver um beijo gay?”.

Retomamos, nesse ponto, a questão do potencial educativo da telenovela, ao dialogar, a partir de sua narrativa, com os dramas particulares de cada um. É o que percebemos nas reflexões suscitadas pelas telenovelas quando nos vemos diante das ponderações da aluna A19 e de outras, como a aluna A22 quando questiona: "E por que é certo passar uma cena de violência e uma cena de amor, não?”. Félix e Clara funcionam como uma janela que possibilita o pensamento para além do que quer ver-se posto e imposto. Por fim, A19 ainda evidenciou a relevância que confere aos meios de comunicação quando garantem visibilidade para temas que não são tão discutidos dentro das famílias:

30. ORLANDI, Eni, op. cit., p. 72.

31. FOUCAULT, Michel. A vontade de saber. São Paulo: Paz e Terra, 2015. (Coleção História da Sexualidade, v. 1).
A19: Eu acho que é muito difícil quebrar algumas coisas que a nossa sociedade tem. Essa desconstrução sobre a homossexualidade, sobre esses temas que não são tão discutidos dentro das famílias, eu acho que é muito bacana quando uma emissora tão importante como a Globo coloca uma coisa dessa. 
Na JSA duas alunas, A19 e A23, trouxeram a relação entre mídia e família homoafetiva, afirmando a importância que veem em uma emissora "grande" como a Globo pautar uma questão que pode encorajar muitos homossexuais a formarem suas próprias famílias. Para elas, quando a homossexualidade é pautada pelos meios de comunicação, as pessoas "se inspiram, acho que elas se desprendem um pouco e se encorajam pra seguir suas vidas, serem felizes e sem pensar, sem ligar pro que os outros vão pensar" (A23).

\section{CONSIDERAÇÕES FINAIS}

Com base na pesquisa quantitativa, depreendemos a forte presença da televisão no cotidiano dos jovens escutados, especialmente da emissora Rede Globo. Ficou evidenciada a importância da telenovela enquanto produto cultural para esses estudantes que afirmaram preferir, da televisão, programas de entretenimento/humor, telenovela e de esporte. Além disso, eles consideram que a televisão influencia as pessoas, tanto positiva quanto negativamente. Elencam, como exemplos, questões que envolvem os embates de minorias sociológicas (tal como a examinada neste artigo, da homossexualidade), o consumo e as formações identitárias. Para eles, a narrativa ficcional, ao construir seus personagens, entra em diálogo com modos de ser e de agir dos telespectadores. Retomamos, nesse aspecto, o que Kellner ${ }^{32}$ coloca enquanto qualidade do telespectador de "criar sua própria leitura e seu próprio modo de apropriar-se da cultura de massa, usando a sua cultura como recurso para fortalecer-se e inventar significados, identidade e forma de vida próprios".

A partir desse levantamento quantitativo realizado nas duas escolas públicas, JSA e PRP, podemos perceber que tanto a imbricação da televisão no cotidiano dos jovens quanto a pauta que realiza, via telenovela, de uma temática tal como a da família homoafetiva garante aos meios de comunicação um espaço de relevância no seio social e os colocam, tal como propugnado pelo campo da comunicação/educação, como agência socializadora das mais importantes na contemporaneidade. Desse modo, ao se propor pensar a realidade, o exame crítico deve, obrigatoriamente, levar em conta o aspecto comunicativo da questão suscitada.

No que concerne à etapa qualitativa da pesquisa, a análise discursiva dos resultados coletados com grupos de discussão realizados com os alunos demonstrou aspectos interessantes, dentre os quais destacamos o fato de considerarem os meios de comunicação como espaço que dialoga com seus anseios e identidades. Isso é visível tanto quando a aluna A19 traz a questão da homossexualidade articulada pela televisão - enquanto um tabu no ambiente familiar - quanto no momento em que os alunos vislumbram nos meios de comunicação um canal para autodescobertas, afirmações e construções de quem são.

Por fim, entendemos que pautar a homossexualidade na telenovela se mostrou de suma importância. Acreditamos que, especialmente no momento da articulação

32. KELLNER, Douglas. A cultura da mídia: estudos culturais - identidade e política entre o moderno e o pós-moderno. São Paulo: Edusc, 2001, p. 11. 
de uma temática contra-hegemônica, abre-se um espaço que fortalece a construção do campo da comunicação/educação com base no que este se propõe em seu essencial: compor um diálogo entre as agências socializadoras - meios de comunicação, família e escola - quando do embate delas para a construção de sentidos sociais, bem como evidencia a relevância que os meios de comunicação têm na busca pela formação dos sentidos sociais na contemporaneidade.

\section{REFERÊNCIAS BIBLIOGRÁFICAS}

BACCEGA, Maria Aparecida. Palavra e discurso: história e literatura. São Paulo: Ática, 1995.

Comunicação \& Educação: do mundo editado à construção do mundo. Comunicação e Informação, Goiânia, v. 2, n. 2, p. 176-187, jul./dez. 1999.

- Narrativa ficcional de televisão: encontro com os temas sociais. Comunicação \& Educação, São Paulo, n. 26, p. 7-16, jan./abr. 2003.

- Comunicação/educação e a construção de uma nova variável histórica. Comunicação \& Educação, São Paulo, v. 14, n. 3, p. 19-28, set./dez. 2009.

BAKTHIN, Mikhail. Marxismo e filosofia da linguagem: problemas fundamentais do método sociológico da linguagem. São Paulo: Hucitec, 2014.

CANCLINI, Néstor García. El consumo cultural en México. México: Grijalbo, 1993.

CONGRESSO BRASILEIRO DE CIÊNCIAS DA COMUNICAÇÃO, 40., 2017, Curitiba. Anais... São Paulo: Intercom, 2017.

FOUCAUlT, Michel. A vontade de saber. São Paulo: Paz e Terra, 2015. (Coleção História da Sexualidade, v. 1).

INSTITUTO BRASIleiro DE GEOGRAFIA E ESTATÍstiCA. População jovem no Brasil. Rio de Janeiro: IBGE, 2004. Disponível em: <https:/ /ww2. ibge.gov.br/home/estatistica/populacao/populacao_jovem_brasil/default. shtm>. Acesso em: 2 jan. 2018.

KELLNER, Douglas. A cultura da mídia: estudos culturais - identidade e política entre o moderno e o pós-moderno. São Paulo: Edusc, 2001.

LOPES, Maria Immacolata Vassalo de. Telenovela como recurso comunicativo. Matrizes, São Paulo, ano 3, n. 1, p. 21-47, ago./dez. 2009.

MEMÓRIA GLOBO. Amor à vida. Rio de Janeiro: Globo, 2014a. Disponível em: $<$ http://memoriaglobo.globo.com/programas/entretenimento/novelas/ amor-a-vida/amor-a-vida-trama-principal.htm>. Acesso em: 2 jan. 2018. 
Em família. Rio de Janeiro: Globo, 2014b. Disponível em: <http:// memoriaglobo.globo.com/programas/entretenimento/novelas/emfamilia/em-familia-trama-principal.htm>. Acesso em: 2 jan. 2018.

ORLANDI, Eni. Análise de discurso: princípios e procedimentos. Campinas: Pontes, 2013.

ROCHA, Camilla Rodrigues Netto da Costa. O conceito de família na telenovela: um estudo sobre sua recepção. 2017. 170 f. Dissertação (Mestrado em Comunicação e Práticas de Consumo) - Escola Superior de Propaganda e Marketing, São Paulo, 2017.

TOALDO, Mariângela; JACKS, Nilda. Consumo midiático: uma especificidade do consumo cultural, uma antessala para os estudos de recepção. In: ENCONTRO ANUAL DA COMPÓS, 22., 2013, Salvador. Anais... Salvador: UFBA, 2013. 
